\title{
Radiation-induced non-targeted response in vivo: role of the TGF $\beta$-TGFBR1-COX-2 signalling pathway
}

\author{
Y Chai ${ }^{1}$, R K K Lam² ${ }^{2}$ G M Calaf ${ }^{2,3}$, H Zhou $^{2}$, S Amundson ${ }^{2}$ and T K Hei ${ }^{*, 1,2}$ \\ ${ }^{1}$ Department of Environmental Health Sciences, Mailman School of Public Health, Columbia University, New York, NY, USA; \\ ${ }^{2}$ Center for Radiological Research, College of Physicians and Surgeons, Columbia University, 630 West 168th Street, New York, \\ NY 10032, USA and ${ }^{3}$ Instituto de Alta Investigación, Universidad de Tarapacá, Arica, Chile
}

Background: Previous studies from our group and others have shown that cyclooxygenase-2 (COX-2) has an essential role in radiation-induced non-targeted responses and genomic instability in vivo. However, the signalling pathways involved in such effects remain unclear.

Methods: A $1 \mathrm{~cm}^{2}$ area $(1 \mathrm{~cm} \times 1 \mathrm{~cm})$ in the lower abdominal region of gpt delta transgenic mice was irradiated with $5 \mathrm{~Gy}$ of $300 \mathrm{keV}$ X-rays. Nimesulide, a selective COX-2 inhibitor, was given to mice for five consecutive days before irradiation. Changes in transforming growth factor-beta (TGF- $\beta$ ) and TGF- $\beta$ receptor type-1 (TGFBR1) mediated signalling pathways, in the out of radiation field lung and liver tissues were examined.

Results: While the plasma level of cytokines remained unchanged, the expression of TGF- $\beta$ and its receptors was elevated in nontargeted lung tissues after partial body irradiation. In contrast to the predominant expression of TGF- $\beta$ in stromal and alveolar cells, but not in bronchial epithelial cells, TGF- $\beta$ receptors, especially TGFBR1 were significantly elevated in non-targeted bronchial epithelial cells, which is consistent with the induction of COX-2. The different expression levels of TGFBR1 between liver and lung resulted in a tissue specific induction of COX-2 in these two non-targeted tissues. Multiple TGF- $\beta$ induced signalling pathways were activated in the non-targeted lung tissues.

Conclusion: The TGF $\beta$-TGFBR1-COX-2 Signalling Pathway has a critical role in radiation-induced non-targeted response in vivo.

Ionising radiation is a well-established human carcinogen and is known to cause tumours in various organs. On the other hand, radiation is a main therapeutic modality in the treatment of a variety of human cancers. In the past two decades, there has been plenty of evidence that radiation can induce bystander/non-target effects in vitro and in vivo. However, the precise mechanisms are still unclear (Morgan, 2007, 2009; Hei et al, 2011). In in vitro studies, there is evidence that reactive oxygen/nitrogen species and cytokines are involved in mediating the non-targeted response in subconfluent cultures or from medium transfer studies. On the other hand, gap junction-mediated cell-cell communications have been shown to be critical for bystander effects in confluent cultures of either human or rodent origin. It is likely that a combination of pathways is involved in producing a bystander response. Using primary human fibroblasts, we showed recently that the cyclooxygenase-2 (COX-2) signalling cascade, including the activation of mitogen activated protein kinase pathways, has an essential role in the bystander process (Zhou et al, 2005). Furthermore, we found that mitochondria had an important role in radiation-induced bystander effect, partially via mitochondria-dependent regulation of iNOS and COX2 signalling pathways, which are under NF- $\kappa \mathrm{B}$ regulation (Zhou et al, 2008). More recently, there is evidence that bone marrow cells of both $\mathrm{CBA} / \mathrm{Ca}$ and $\mathrm{C} 57 \mathrm{BL} / 6$ mice are responsive to signals produced by either irradiated $\mathrm{CBA} / \mathrm{Ca}$ or C57BL/6 mice, and the responses are mediated by the cytokines converging on a COX-2 dependent pathway (Rastogi et al, 2012).

*Correspondence: Professor TK Hei; E-mail: tkh1@columbia.edu

Received 15 November 2012; revised 15 January 2013; accepted 17 January 2013; published online 14 February 2013

(c) 2013 Cancer Research UK. All rights reserved 0007-0920/13 
Using gpt delta transgenic mice, we reported recently that radiation can induce DNA damage and mutagenesis in the out of field lung and liver tissues after a $5 \mathrm{~Gy}$ dose of X-rays delivered to the lower abdomen of otherwise shielded animals. Furthermore, the induction of COX-2 coincided with an increase in prostaglandin and spi mutations in out of field lung tissues (Chai et al, 2012). As a follow-up study, here, we examined the possible pathways involved in partial body irradiation induced non-targeted responses in $g p t$ delta transgenic mice.

\section{MATERIALS AND METHODS}

Animal and drug treatment schedule. Nimesulide (Sigma Aldrich, St Louis, MO, USA), a selected COX-2 inhibitor (Famaey, 1997), was dissolved in PBS containing 0.2\% DMSO, freshly prepared on the day of the experiments. Four groups of adult male $g p t$ delta transgenic mice were used in this study. There were two non-irradiated groups, consisting of three animals each, treated with vehicle (PBS with 0.2\% DMSO, used for dilution of Nimesulide, $0.3 \mathrm{ml}$ per animal, intraperitoneal injection) or Nimesulide $\left(0.3 \mathrm{ml}\right.$ per animal, $1.5 \mathrm{mg} \mathrm{kg}^{-1}$, intraperitoneal injection) only. The other two parallel groups were partial body irradiated with $5 \mathrm{~Gy}$ of X-rays as described previously (Chai et al, 2012) after pretreatment by vehicle or Nimesulide. Each partial body irradiation group consisted of five mice. To be consistent with our previous study, a 5 Gy dose was chosen in the current work. On the other hand, treatments with gamma-knife for CNS tumours and with hadrontherapy for other solid tumours involved doses in excess of 10-15 Gy in a single fraction been used with the intent to cure (Miyamoto et al, 2007; Han et al, 2012). As such, with modern advances in radiotherapy regimen, doses larger than 2 Gy fractions are no longer clinically irrelevant. All of the drugs were administered for five consecutive days. The last treatment of drugs was given $2 \mathrm{~h}$ before irradiation. Animals in the four groups were sacrificed at $24 \mathrm{~h}$ after irradiation. Lung and liver tissues were collected and processed for further molecular studies. A portion of each tissue was frozen in liquid nitrogen while the rest of each tissue was fixed in $10 \%$ formalin.

Western blot analysis. Cell lysates (50-100 $\mu \mathrm{g}$ protein) were resolved on 4-12\% gradient SDS-PAGE gel (Invitrogen, Carlsbad, CA, USA), and processed according to standard protocols. Various antibodies were used, including anti-COX-2 (Cayman, Ann Arbor, MI, USA), anti-TGF- $\beta 1$ (Cell Signaling, Danvers, MA, USA), antiTGF- $\beta$ receptor type- 1 (TGFBR1) (Abcam, Cambridge, MA, USA), anti-TGF- $\beta$ receptor type-2 (TGFBR2) (Santa Cruz Biotech, Santa Cruz, CA, USA), anti-TNF- $\alpha$ (Cell Signaling), anti-TNF receptor 1(TNF-R1) (Santa Cruz Biotech), anti-extracellular signal-regulated kinase (ERK) (Cell Signaling), anti-phosphoERK(Thr $\left.{ }^{202} / \mathrm{Tyr}^{204}\right)$, (Cell Signaling), anti-c-Jun N-terminal kinase (JNK) (Cell Signaling), anti-phospho-JNK(Thr ${ }^{183} / \mathrm{Tyr}^{185}$ ) (Cell Signaling), anti- nuclear factor kappa-B (NF $\kappa$ B) p65 (Cell Signaling), anti-phospho-NF $\kappa$ B p65(Ser ${ }^{536}$ ) (Cell Signaling), antiAKT (Cell Signaling), anti-phospho-AKT(Ser ${ }^{473}$ ) (Cell Signaling), anti-Smad2 (Cell Signaling), anti-phosho-Smad2(Ser ${ }^{465 / 467}$ ) (Cell Signaling), anti-Rac1/2/3 (Cell Signaling), anti-phosho-Rac1/ $\operatorname{cdc} 42\left(\mathrm{Ser}^{71}\right)$ (Cell Signaling) and monoclonal anti- $\beta$-actin (Sigma Aldrich) (optimal dilutions of antibodies were 1:100-1:1000). The secondary antibodies (anti-rabbit or anti-mouse, GE Healthcare, Piscataway, NJ, USA) were conjugated with horseradish peroxidase (HRP) (dilution 1:5000). Chemiluminescent signal was detected using the ECL system (GE Healthcare) and quantified using Image J software (NIH, Bethesda, MD, USA) and normalised to the $\beta$ actin expression level.

Immunohistochemistry staining. Immunohistochemistry staining was performed using various primary antibodies and specific secondary antibodies including anti-COX-2 (Cayman), anti-8OHdG (Abcam), anti-TGF- $\beta 1$ (Sigma Aldrich), anti- TGFBRI (Abcam) and anti-phosho-ERK (Cell Signaling) as previously described (Calaf et al, 2008). The slides were analysed by using an Olympus CX31 microscope connected with a Motic MC Camera (2.0 megapixel; MC2001interface, Sterling Heights, MI, USA). Paint Shop Pro (Sterling Heights, MI, USA) was used to quantify the protein expression level on each slide (Calaf et al, 2008). The data were expressed as the mean \pm s.e. of the mean (s.e.m.) of the relative grade of luminescence obtained from each slide.

Enzyme-linked immunosorbent assay (ELISA). Microwell plates (Nunc Maxisorp, eBioscience, San Diego, CA, USA) were coated with $100 \mu \mathrm{l}$ of capture antibody in coating buffer (Invitrogen) overnight at $4{ }^{\circ} \mathrm{C}$. For blocking, $200 \mu \mathrm{l}$ of $3 \%$ bovine serum albumin (BSA) in PBS was added to wells and incubated for $1 \mathrm{~h}$ at $20^{\circ} \mathrm{C}$. Plasma was diluted 1:5 in 2\% BSA in PBS containing 0.05\% Tween 20 (PBST) to the wells followed immediately by addition of biotinconjugated detection antibody, diluted in $50 \mu \mathrm{l}$ of $2 \%$ BSA-PBST. After $90 \mathrm{~min}$ incubation at $20^{\circ} \mathrm{C}$ with shaking, plates were washed $(4 \times$ PBST $)$ and streptavidin-HRP was added, diluted in $100 \mu \mathrm{l}$ of $2 \%$ BSA-PBST. Following $1 \mathrm{~h}$ incubation at $20^{\circ} \mathrm{C}$, microwells were washed four times and $100 \mu \mathrm{l}$ of tetramethylbenzidine (TMB, Thermo Scientific, Rockford, IL, USA) added for 15-30 min at $20^{\circ} \mathrm{C}$. Reactions were stopped by addition of $0.9 \mathrm{M} \mathrm{H}_{2} \mathrm{SO}_{4}(50 \mu \mathrm{l})$ and product absorbance was determined at $450 \mathrm{~nm}$ (Partridge et al, 2010).

Statistical analysis. All data were expressed as mean \pm s.e. of mean. Differences between groups were tested for statistical significance using a Student's $t$-test. A $P$-value less than 0.05 denoted the presence of a statistically significant difference between groups.

\section{RESULTS}

Role of COX-2 inhibitor in lower abdominal irradiationinduced DNA damage in out of field lung tissues. Consecutive pretreatment with Nimesulide $\left(1.5 \mathrm{mg} \mathrm{kg}^{-1}\right.$ body weight, intraperitoneal injection) for 5 days did not affect COX-2 expression in lung tissues of non-irradiated animals (Figure 1A). In our previous study, we found that both female and male animals showed a similar induction peak of COX-2 at $24 \mathrm{~h}$ after irradiation (Chai et al, 2012). In contrast, pretreatment of Nimesulide reduced COX2 expression in non-targeted lung tissues by $30 \%$ relative to vehicle control animals at $24 \mathrm{~h}$ after lower abdominal irradiation (Figure 1A). Similar to western blot, results from immunohistochemistry staining showed a $30 \%$ suppression efficiency of COX-2 in non-targeted lung bronchial epithelial cells by Nimesulide, relative to the vehicle pretreated group at $24 \mathrm{~h}$ after partial body irradiation $(P<0.05$, Figure $1 \mathrm{~B})$. Compared with the vehicle control group, Nimesulide reduced induction of $\mathrm{PGE}_{2}$, a major isoform of prostaglandin by $30 \%$ in bystander lung tissues (3.9-fold vs 2.6-fold, respectively, Figure 1C). The efficiency of $\mathrm{PGE}_{2}$ suppression by Nimesulide was consistent with that of COX-2 among the same non-targeted lung tissues after lower abdominal irradiation. As a consequence of inhibiting the production of prostaglandin, Nimesulide efficiently reduced radiation-induced oxidative DNA damage in non-targeted lung tissues by $40 \%$ compared with vehicle group after lower abdominal irradiation $(P<0.05$, Figure 1D).

Alteration of Cytokines and their receptors in plasma and bystander tissues after partial body irradiation. The plasma levels of released cytokines, especially TGF- $\beta$ and TNF- $\alpha$, after PBIR were examined using ELISA. A fluctuation of both cytokines in plasma at a series of time points after PBIR was observed 
A
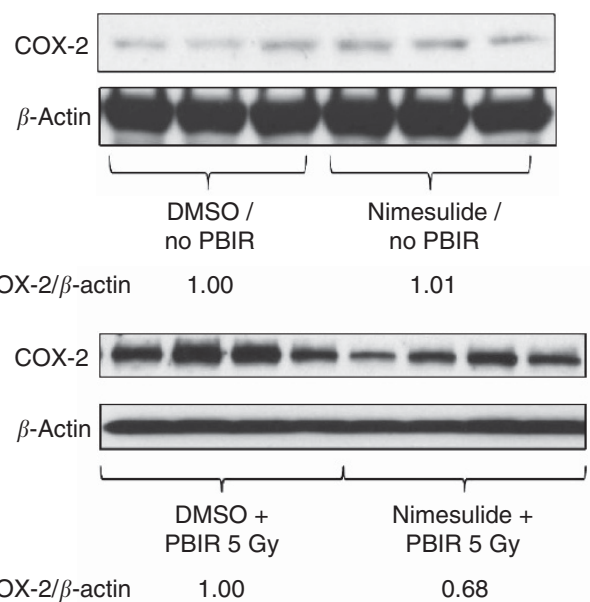

C

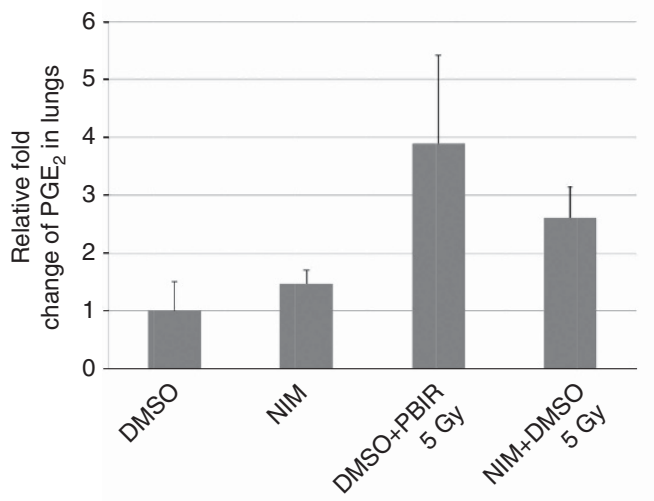

B

COX-2 induction

DMSO+PBIR
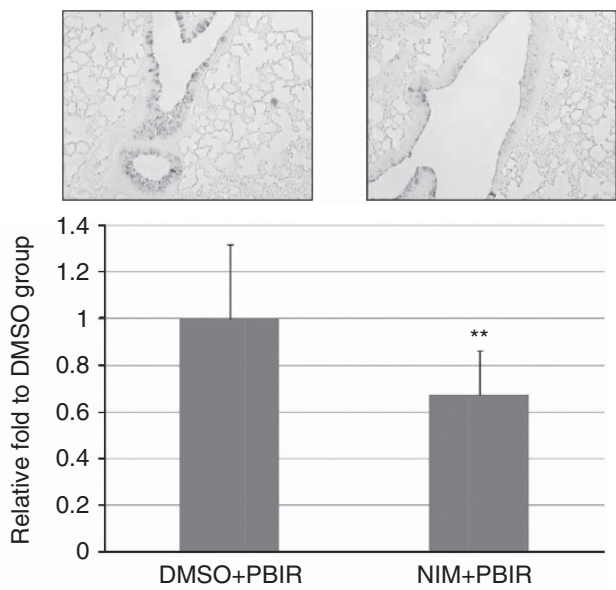

D
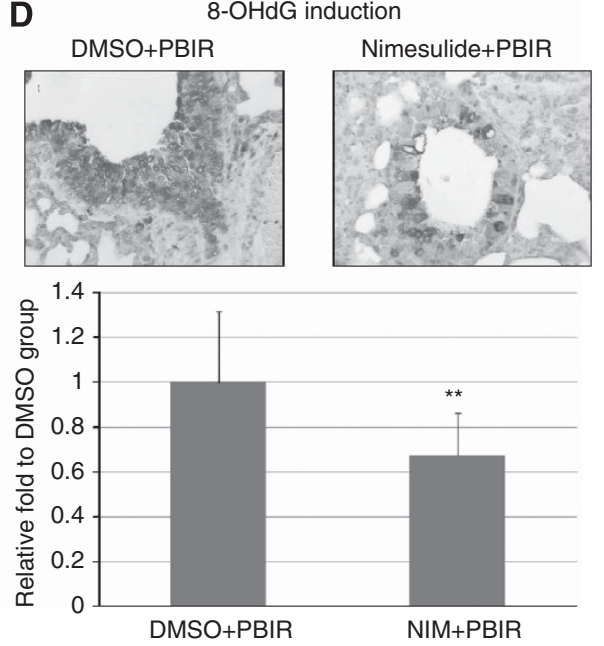

Figure 1. Pretreatment of COX-2 inhibitor suppresses induction of COX-2, PGE2 and 8-OHdG in non-targeted lung tissues after partial body irradiation. (A) Western blot data show pretreatment with Nimesulide did not affect COX-2 basal expression in lung tissues but reduced COX-2 expression levels in non-targeted lung tissues $24 \mathrm{~h}$ after lower abdominal irradiation. (B) COX-2 was significantly reduced in non-targeted bronchial epithelial cells at $24 \mathrm{~h}$ after partial body irradiation. A representative microscopic field from each group is shown under $10 \times$ magnification. Bar represents $200 \mu \mathrm{m}$. (C) Nimesulide reduced PGE2 production in non-targeted lung tissues. Pooled data from three animals and error bars: means \pm s.e.m. Quantification of COX-2 staining intensity in bronchial epithelial cells in Nimesulide-treated mice showed a significant reduction relative to controls with asterisks ( ${ }^{*} P<0.01$, student's $t$ test). (D) Pretreatment with Nimesulide suppressed the induction of $8-O H d G$ in nontargeted lung tissues. 8-OHdG was localised predominantly in bronchial epithelial cells at $24 \mathrm{~h}$ after partial body irradiation. A representative microscopic field from each group is shown under $40 \times$ magnification. Bar represents $50 \mu \mathrm{m}$. Statistical comparison between DMSO and Nimesulide groups with similar partial body irradiation is marked with asterisks (** $P<0.01$, Student's t-test). Error bars indicate standard errors of the means (s.e.m.) for 20 independent microscopic fields from three different mice.

although the difference was not statistically significant comparing with the levels in controls (Figures 2A and B). Further, we examined the expression level of ligands and related receptors of TGF- $\beta$ and TNF- $\alpha$ in lung tissues using western blots after PBIR. As shown in Figure $3 \mathrm{~A}$, TGF- $\beta$ expression was significantly elevated in bystander lung tissues at $24 \mathrm{~h}$ after partial body irradiation, but decreased at $48 \mathrm{~h}$. Following the upregulation of TGF- $\beta$, TGF- $\beta$ receptors, especially TGFBR1, were gradually elevated in bystander lung tissues at $48 \mathrm{~h}$ after irradiation and decreased to basal level at $72 \mathrm{~h}$ (Figure 3B). Quantification analysis of western blot bands showed that TGF- $\beta$ ligands responded earlier than TGFBR1 and TGFBR2, respectively (Figure 3B). In contrast, expression of TNF- $\alpha$ ligands and receptors in bystander lung tissues was not significantly different from that in the non-treated lung tissues at a series of time points after partial body irradiation (Figure 3C). Consistent with our previous finding that COX-2 induction was tissue-specific but not gender-specific (Chai et al,
2012), there was a difference in the expression of TGF- $\beta$ receptor levels between non-targeted livers and lungs of the same animals. There was a negligible level of TGFBR1 in liver tissue but a high level in lung tissues, which might result in different sensitivity of TGF- $\beta$ signals in lung $v$ s liver (Figure 3D). The difference in TGF$\beta$ receptors was consistent with different induction of COX-2 and DNA damage response in bystander lung and liver tissues after treatment, as shown previously (Chai et al, 2012).

Using immunohistochemistry staining, we determined the location of TGF- $\beta$ ligands and receptors in non-targeted lung tissues after PBIR. As all end points obtained with a $6 c$ Gy dose of WBIR (control for scattering dose) were similar to non-irradiated controls, the result obtained with the $6 c$ Gy dose was shown. TGF$\beta 1$ was predominantly expressed in stromal and alveoli cells but not in bronchial epithelial cells of both scattered dose control and PBIR 5 Gy groups (Figures 4A and B). In contrast to the induction of COX-2 shown earlier, there was no significant difference in the 
distribution of TGF- $\beta$ in lung tissues after PBIR $v s$ the scattering dose WBIR group. Quantification analysis did not show a significant difference in the expression of TGF- $\beta$ in bronchial epithelial cells between non-irradiated control and partially irradiated animals (PBIR $5 \mathrm{~Gy}$, data not shown). In contrast to
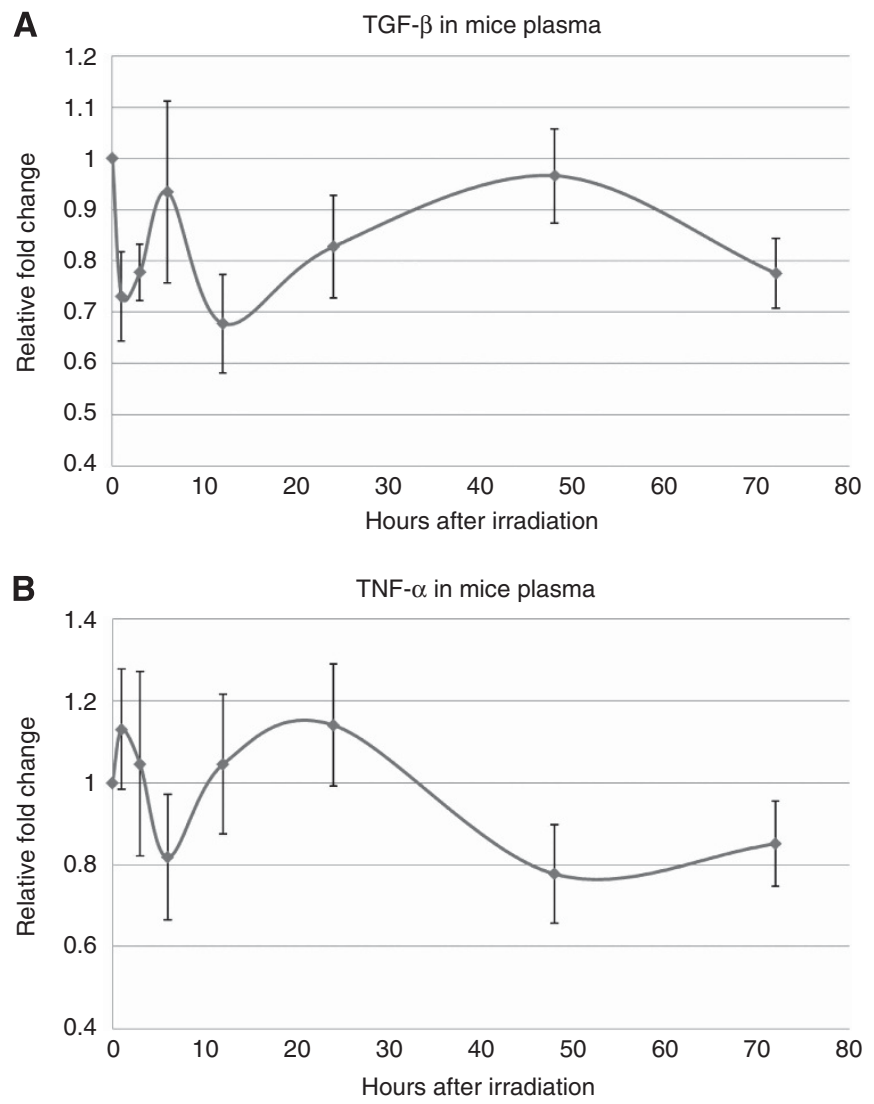

Figure 2. Changes of cytokines in plasma after partial body irradiation. Time course of the released forms of TGF- $\beta$ (A) and TNF- $\alpha$ (B) in plasma after lower abdomen irradiation with $5 \mathrm{~Gy}$ of $\mathrm{X}$-rays is shown. Three animals per dosage and time point were analysed.

the results obtained with TGF- $\beta$, TGFBR1 was found to distribute mainly in bronchial epithelial cells but not in neighbouring stromal cells (Figures 4C and D). TGFBR1 was significantly increased in non-targeted lung bronchial epithelial cells compared with controls, which was consistent with the expression pattern and location of COX-2 induced by partial body irradiation.

Activation of multiple TGF- $\beta$ induced pathways in non-targeted lung tissues. There are two major TGF- $\beta$ related signalling pathways, Smad-dependent and Smad-independent pathways. Activation of TGF- $\beta$ signalling leads to the induction of multiple signalling pathways involving Smad2, Rac1, ERK, JNK, NF $\kappa \mathrm{B}$ and AKT as described (Wrzesinski et al, 2007). The expression of Smad2, an important factor in the Smad-dependent TGF- $\beta$ pathway in bystander lung tissues was examined after PBIR at different time points. p-Smad2 levels were elevated at $24 \mathrm{~h}$ after treatment and maintained through $48 \mathrm{~h}$ before returning to basal levels at $72 \mathrm{~h}$ after irradiation, consistent with the induction of TGF- $\beta$ and COX-2 in the non-targeted lung tissues (Figure 5A).

Besides the Smad-dependent pathway, we examined the Smadindependent signalling pathways involving Rac1, ERK, JNK, AKT and $\mathrm{NF} \kappa \mathrm{B}$ (Ivanov et al, 2010). Rac1 did not show any changes in non-targeted lung tissues at a series of time points after irradiation (Figure 5A). In contrast, $\mathrm{NF} \kappa \mathrm{B}, \mathrm{AKT}$, ERK and JNK, were activated by phosphorylation, which are critical upstream events controlling COX-2 expression. The activated forms of $\mathrm{NF} \kappa \mathrm{B}, \mathrm{AKT}$, ERK and JNK were all dramatically upregulated in bystander lung tissues at different time points after PBIR (Figures 5B-E). Phosphorylation of p65 signified an upregulation of NF $\kappa$ B activity at $3 \mathrm{~h}$ after treatment and that was maintained above basal levels within $24 \mathrm{~h}$ after irradiation, indicating a persistent response in non-targeted lung tissues to the signals derived from the irradiated area (Figure $5 \mathrm{~B}$ ). Similar to $\mathrm{NF} \kappa \mathrm{B}$, AKT showed activation in bystander lung tissues at a series of time points after treatment (Figure 5C). Similarly, expression of ERK and JNK showed a biphasic pattern in the bystander lung tissues with an initial peak induction at $1 \mathrm{hr}$ after irradiation and a later, more sustained secondary peak at $24-48 \mathrm{~h}$ before returning to basal levels at $72 \mathrm{~h}$ (Figures 5D and E). Immunohistochemistry staining showed that p-ERK was predominantly localised in non-targeted bronchial epithelial cells, consistent with induction of COX-2 and TGFBR1 at $24 \mathrm{~h}$ after lower abdomen irradiation (Data not shown).
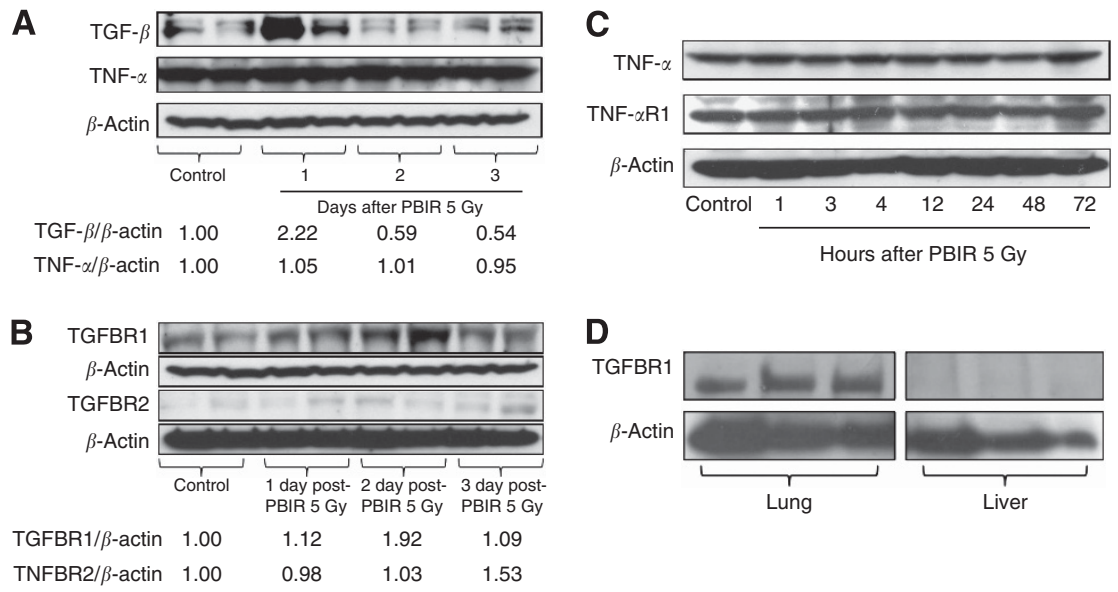

Figure 3. TGF- $\beta$ but not TNF- $\alpha$ is induced in bystander lung tissues after lower abdominal irradiation. (A) Western blot data show expression of TGF- $\beta$ and TNF- $\alpha$ in non-targeted lung tissues as a function of day postirradiation. Quantification of relative fold changes of TGF- $\beta$ and TNF- $\alpha$ expression relative to $\beta$-actin of each group is shown. (B) Similar to A, but showing expression levels of TGFBR1 and TGFBR2 in non-targeted lung tissues at different time points postirradiation. (C) Western blot data showing expression levels of TNF- $\alpha$ and TNF- $\alpha$ receptor 1 in bystander lung tissue as a function of time post-irradiation. $\beta$-actin levels were used as a loading control. (D) Different expression level of TGFBR1 in lung and liver tissues. Lungs and livers are from three independent non-irradiated animals from control group. 
A

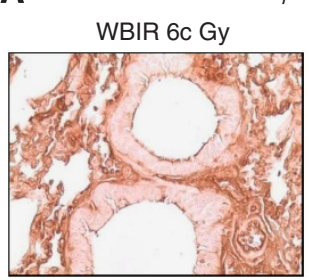

B

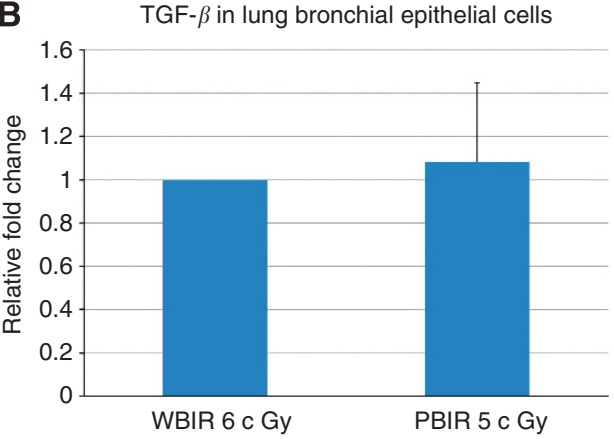

C TGFBR1 staining

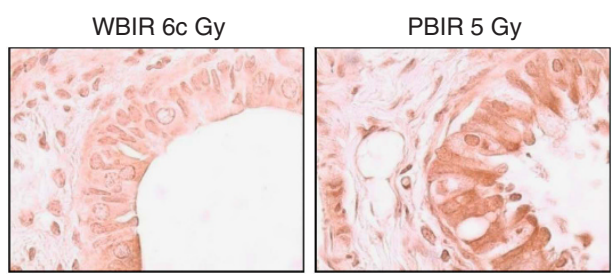

D TGFBR1 in lung bronchial epithelial cells

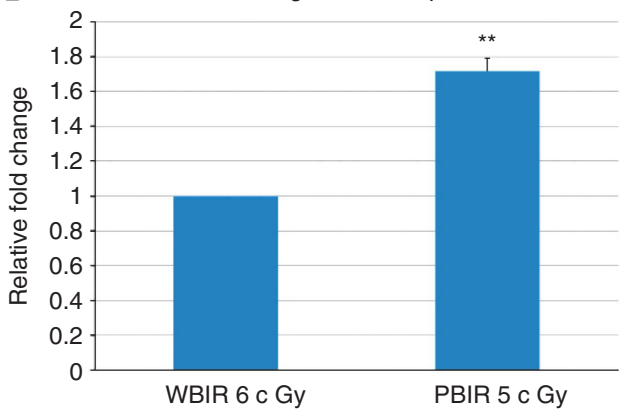

Figure 4. Differential distribution of TGF- $\beta$ and TGFBR1 in non-targeted lung tissues. (A) Representative immunohistochemical staining of TGF- $\beta$ in lung tissue section of animals irradiated with a whole-body dose of 6cGy (scattering dose) of X-rays (left) and those from partial body irradiated animals (right) under $40 \times$ magnification. Bar represents $50 \mu \mathrm{m}$. (B) Quantification of TGF- $\beta$ staining in bronchial epithelial cells of each group. The whole-body irradiated group receiving a 6cGy scattering dose of X-rays, which gave similar expression levels as non-irradiated animals, was used as controls. (C) and (D) Similar to descriptions for A and B but for TGFBR1 expression, under $40 \times$ magnification. Bar represents $20 \mu \mathrm{m}$. Statistical comparison between control and irradiation groups marked with asterisks ( ${ }^{\star} P<0 \cdot 05$, Student's t-test). Error bars indicate the s.e. of the mean (s.e.m.) for 20 independent microscopic fields from three different mice.

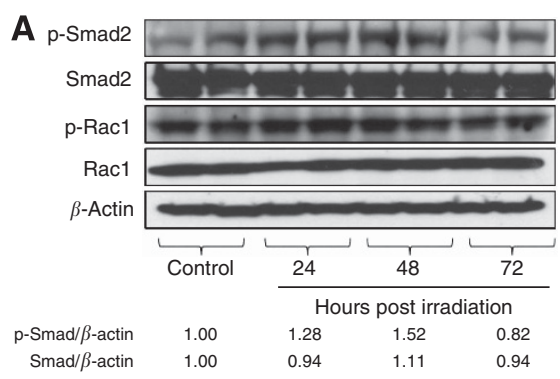

B p-p65 - - - - -

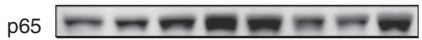

$\beta$-Actin

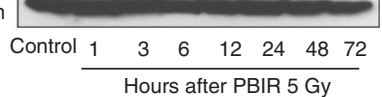

p-p65/B-actin $\begin{array}{lllllllll}1.00 & 0.64 & 1.14 & 1.37 & 1.23 & 1.06 & 1.01 & 1.26\end{array}$

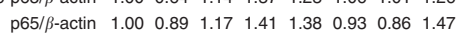

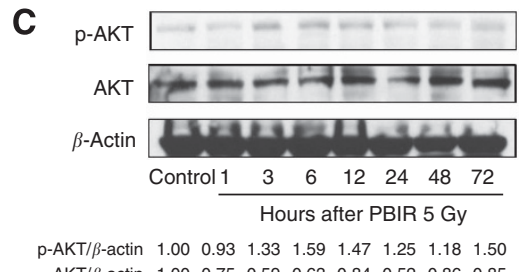

AKT/P-actin $1.000 .93 \quad 0.53 \quad 0.03 \quad 0.84$ 0.52 0.86

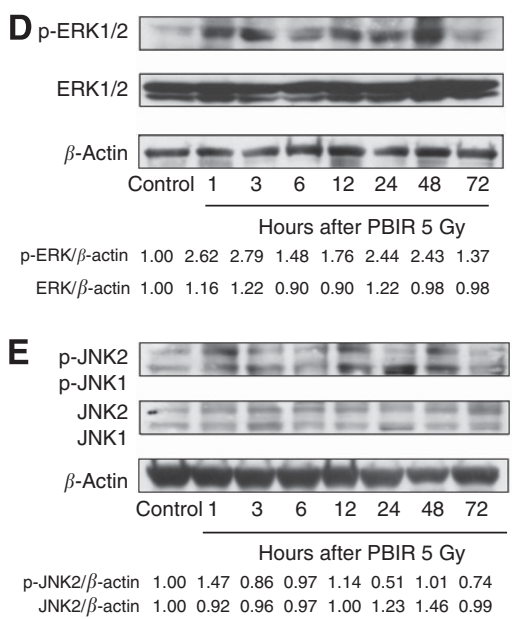

$\begin{array}{lllllllll}\text { p-JNK2/ } / \text {-actin } & 1.00 & 1.47 & 0.86 & 0.97 & 1.14 & 0.51 & 1.01 & 0.74 \\ \text { JNK2/ } \beta \text {-actin } & 1.00 & 0.92 & 0.96 & 0.97 & 1.00 & 1.23 & 1.46 & 0.99\end{array}$

Figure 5. Activation of multiple TGF- $\beta$ related signalling pathways in non-targeted lung tissues. (A) Western blot data show expression of phosphorylated-Smad-2 but not phosphorylated-Rac1 in non-targeted lung tissues. (B-E) Activation of Smad-independent pathways in nontargeted lung. The kinetics of activation of ERK, JNK, NF $\kappa$ B and AKT in non-targeted lung tissues is shown. A total of three animals were used per time point and representative expression level from a single animal is shown. The rest of the animals of each group demonstrated similar trends. Beta-actin levels were used as loading controls in all samples. 


\section{DISCUSSION}

We have shown previously that the induction of COX-2 in bystander lung tissue is tissue-specific, but not gender dependent (Chai et al, 2012). Tissue-specific bystander effects have also been shown in other in vivo systems. Previous studies have shown that partial body irradiation induced different epigenetic responses in bystander organs such as skin and spleen (Ilnytskyy et al, 2009), whereas no differential response was seen in the same organism by acute $v$ fractionated exposure. There is evidence that whole-body irradiation of animals by either X-rays or $\gamma$-rays significantly induces an increase in TNF- $\alpha$ and a decrease in TGF- $\beta$ levels in plasma (Partridge et al, 2010). Our present studies show that liver, in contrast to the lung, showed no induction of TGFBR1 and lacks the subsequent downstream signalling responses, including JNK and $\mathrm{NF} \kappa \mathrm{B}$, that are necessary for the induction of COX-2 as shown previously (Zhou et al, 2005). The lack of receptor provides a reasonable explanation for the differential induction of COX-2 levels between the lung and the liver in partially irradiated animals.

There are two possible pathways whereby signals from irradiated lower abdomen can be transmitted to non-targeted lung tissues. The first involves release of cytokine(s) from irradiated tissues/organs in the lower abdomen, circulation to non-targeted lung tissues and binding to their receptors on the corresponding cells to induce bystander effects such as upregulation of COX-2 and DNA damage in non-targeted lung tissues. Therefore, the change of cytokines in plasma could be associated with the upregulation of COX-2 in non-targeted lung tissues. However, our preliminary ELISA analysis did not show any significant change in the plasma level of either TGF $\beta$ or TNF $\alpha$ as a function of time postpartial body irradiation whereas COX-2 was shown to be significantly induced in non-targeted lung tissues. A second possible mechanism of transferring damage signals is through circulation of lymphatic cells from exposed regions in the lower abdomen of animals to non-targeted lung tissues to activate downstream effects such as induction of COX-2 and DNA damage response. COX-2 is over-expressed with chronic inflammation and infiltration of macrophages, neutrophils and lymphocytes (Desouza et al, 2005). Previous studies have shown that cytokines, especially TGF- $\beta$, are induced in lung tissues during acute inflammation (Xing et al, 1994). Interestingly, from the present studies, over-expression of TGF- $\beta$ receptors did not colocalise with TGF- $\beta$ in the same regions of bystander lung tissues. TGF- $\beta$ was highly expressed in lung bronchial stromal cells and alveoli cells but TGF- $\beta$ receptors were predominantly localised in bronchial epithelial cells where they colocalised with the induction of COX-2 and oxidative DNA damage after lower abdominal irradiation. There is evidence that TGF- $\beta$ is involved in ROS induction and $\mathrm{Ca}^{2+}$ influx in bystander cells (Shao et al, 2006; Shao et al, 2008) and inhibition of TGF- $\beta$ or ROS can reduce the bystander responses in cells. While the rationale for the differential expression of TGF- $\beta$ and its receptors in specific bystander cell types is not known, it is clear that the TGF- $\beta$ signalling pathway is involved in bystander responses in non-targeted lung tissues.

As demonstrated in the present studies, multiple TGF- $\beta$ related signalling pathways, both Smad-dependent and Smad-independent, including Smad2, ERK, JNK, NF $\kappa$ B (p65) and AKT, are activated in non-targeted lung tissues after lower abdominal irradiation. However, the expression kinetics appears to be different for each pathway. The expression of the Smad-2 pathway showed that there was only one peak within 3 days after irradiation, consistent with the change of TGF- $\beta$ ligands and receptors in non-targeted lung tissues. In contrast, all the Smadindependent pathways examined, showed a biphasic expression profile, reminiscent of that reported for $\mathrm{NF} \kappa \mathrm{B}$ regulated gene expression in human bystander lung cells in vitro (Ghandhi et al,
2008; 2011). In the bystander lung tissues, the change in Smadindependent pathways is more complicated than in Smaddependent pathways possibly because the former could be simultaneously regulated by other factors, but Smad-dependent pathways were primarily controlled by TGF- $\beta$.

On the basis of the in vivo results of this study, a working model of the signalling pathway for the radiation-induced bystander effect in non-targeted lung tissues after lower abdominal irradiation is proposed (Figure 6). After irradiation of the lower abdomen, irradiated lymphatic cells circulate and infiltrate into non-targeted lung tissues to induce expression of TGF- $\beta$ ligands and receptors in different regions of the non-targeted lung tissues. The TGF- $\beta$ ligands in stromal and alveoli cells bind to TGFBR1 in the bronchial epithelial cells to activate multiple downstream signalling pathways such as ERK, JNK, NF $\kappa \mathrm{B}$, AKT and Smad2. Consequently, COX-2 is induced in non-targeted lung tissues, especially bronchial epithelial cells. COX-2 catalyses arachidonic acid to produce prostaglandin and further induces oxidative DNA damage in bronchial epithelial cells. Our current study highlights the importance of COX-2 as a mediator of in vivo non-targeted responses. Earlier studies by (Mancuso et al, 2008) showed the induction of tumorigenesis in the brain after irradiation of the lower halves of neonatal Ptch $1^{+/-}$mice. Furthermore, their studies also indicated that pretreatment with a single dose of Nimesulid $\left(1.5 \mathrm{mg} \mathrm{kg}^{-1}\right)$ induced a non-significant reduction in apoptosis and double strand breaks in non-targeted brain tissues. However, the study was inconclusive since only a single dose was applied. There was not enough evidence to show that pretreatment with COX-2 inhibitor suppressed the activity of COX-2 in brain tissues efficiently as a result of rapid clearance/degraded activity. Considering different biological end points, radiation induced nontargeted response in vivo appears to be a tissue specific observation. In the present study, a consecutive five day treatment regimen reduced the COX-2 as well as 8 -OHdG levels in non-targeted bronchial epithelial cells by $30 \%(P<0.05)$.

A better understanding of the mechanisms of non-targeted effects will be invaluable to assess the clinical relevance of bystander effects and ways in which the bystander phenomenon can be manipulated to increase therapeutic gain in radiotherapy.
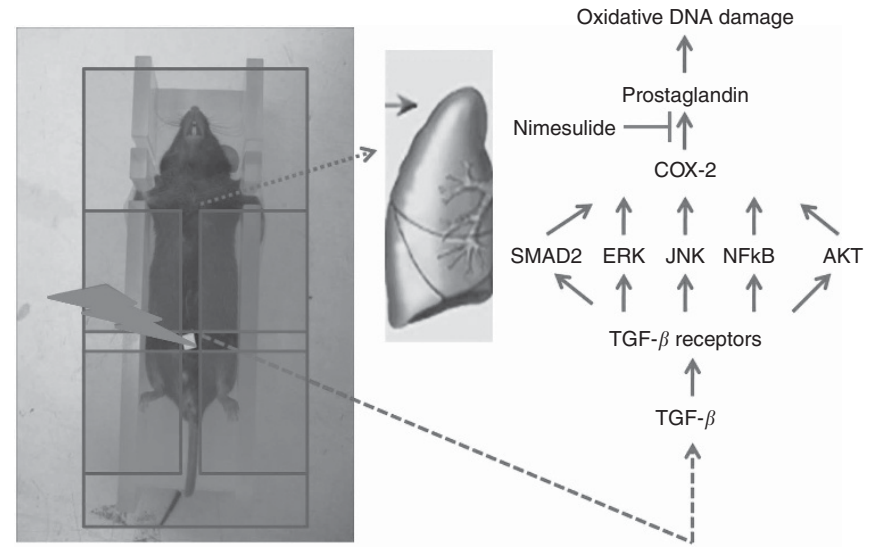

Figure 6. A signalling model for the induction of non-targeted responses in the out of field lung tissues after lower abdomen irradiation. Lower abdomen irradiation induces TGF- $\beta$ ligands and receptors in non-targeted lung tissues but not released forms in the blood. TGF- $\beta$ in stromal regions binds to its corresponding receptors on bronchial epithelial cells and activates a range of signalling pathways involving ERK, JNK, AKT, NF $\kappa$ B and Smad2, which lead to the upregulation of COX-2 in non-targeted lung tissues. COX-2 further induces prostaglandin production, oxidative DNA damage and mutagenesis in the non-targeted lung tissues. 


\section{ACKNOWLEDGEMENTS}

Work was supported by the funding from National Institutes of Health grants CA 49062, ES 12888, NIH Resource Center Grant RR 11623 and Environmental Center Grant ES 09089.

\section{CONFLICT OF INTEREST}

The authors declare no conflict of interest.

\section{REFERENCES}

Calaf GM, Echiburu-Chau C, Zhao YL, Hei TK (2008) BigH3 protein expression as a marker for breast cancer. Int J Mol Med 21: 561-568.

Chai Y, Calaf MC, Zhou H, Ghandhi SA, Elliston CD, Wen G, Nohmi T, Amundson SA, Hei TK (2012) Radiation induced COX-2 expression and mutagenesis at non-targeted lung tissues of $g p t$ delta transgenic mice. $\mathrm{Br} J$ Cancer 108(1): 91-98.

Desouza IA, Franco-Penteado CF, Camargo EA, Lima CS, Teixeira SA, Muscara MN, De Nucci G, Antunes E (2005) Inflammatory mechanisms underlying the rat pulmonary neutrophil influx induced by airway exposure to staphylococcal enterotoxin type A. Br J Pharmacol 146: 781-791.

Famaey JP (1997) In vitro and in vivo pharmacological evidence of selective cyclooxygenase- 2 inhibition by nimesulide: an overview. Inflamm Res $\mathbf{4 6}$ : 437-446.

Ghandhi SA, Sinha A, Markatou M, Amundson SA (2011) Time-series clustering of gene expression in irradiated and bystander fibroblasts: an application of FBPA clustering. BMC Med Genomics 12: 2.

Ghandhi SA, Yaghoubian B, Amundson SA (2008) Global gene expression analyses of bystander and alpha particle irradiated normal human lung fibroblasts: synchronous and differential responses. BMC Med Genomics 1: 63.

Han J, Girvigian MR, Chen JCT, Miller MJ, Lodin K, Rahimian J, Arellano PA, Cahan BL, Kaptein JS (2012) A Comparative Study of Stereotactic Radiosurgery, Hypofractionated, and Fractionated Stereotactic Radiotherapy in the Treatment of Skull Base Meningioma. Am J Clin Oncol Dec; e-pub ahead of print 13 December 2012.

Hei TK, Zhou H, Chai Y, Ponnaiya B, Ivanov VN (2011) Radiation induced non-targeted response: mechanism and potential clinical implications. Curr Mol Pharmacol 4: 96-105.

Ilnytskyy Y, Koturbash I, Kovalchuk O (2009) Radiation-induced bystander effects in vivo are epigenetically regulated in a tissue-specific manner. Environ Mol Mutagen 50: 105-113.

Ivanov VI, Zhou H, Ghandhi SA, Karasic TB, Yaghoubian B, Amundson SA, Hei TK (2010) Radiation-induced bystander signaling pathways in human fibroblasts: a role for interleukin-33 in the signal transmission. Cell Signal 22: 1076-1087, Epub 2010 Mar 3.
Mancuso M, Pasquali E, Leonardi S, Tanori M, Rebessi S, Di Majo V, Pazzaglia S, Toni MP, Pimpinella M, Covelli V, Saran A (2008) Oncogenic bystander radiation effects in Patched heterozygous mouse cerebellum. Proc Natl Acad Sci USA 105: 12445-12450.

Miyamoto T, Baba M, Sugane T, Nakajima M, Yashiro T, Kagei K, Hirasawa N, Sugawara T, Yamamoto N, Koto M, Ezawa H, Kadono K, Tsujii H, Mizoe JE, Yoshikawa K, Kandatsu S, Fujisawa T. Working Group for Lung Cancer (2007) Carbon ion radiotherapy for stage I non-small cell lung cancer using a regimen of four fractions during 1 week. $J$ Thorac Oncol 2: 916-926.

Morgan WF, Sowa MB (2007) Non-targeted bystander effects induced by ionizing radiation. Mutat Res 616: 159-164.

Morgan WF, Sowa MB (2009) Non-targeted effects of ionizing radiation: implications for risk assessment and the radiation dose response profile. Health Phys 97: 426-432.

Partridge MA, Chai Y, Zhou H, Hei TK (2010) High-throughput antibodybased assays to identify and quantify radiation-responsive protein biomarkers. Int J Radiat Biol 86: 321-328.

Rastogi S, Coates PJ, Lorimore SA, Wright EG (2012) Bystander-type effects mediated by long-lived inflammatory signaling in irradiated bone marrow. Radiat Res 177: 244-250.

Shao C, Folkard M, Prise KM (2008) Role of TGF-betal and nitric oxide in the bystander response of irradiated glioma cells. Oncogene 27: 434-440.

Shao C, Lyng FM, Folkard M, Prise KM (2006) Calcium fluxes modulate the radiation-induced bystander responses in targeted glioma and fibroblast cells. Radiat Res 166: 479-487.

Wrzesinski SH, Wan YY, Flavell RA (2007) Transforming growth factor-beta and the immune response: implications for anticancer therapy. Clin Cancer Res 13: 5262-5270.

Xing Z, Jordana M, Kirpalani H, Driscoll KE, Schall TJ, Gauldie J (1994) Cytokine expression by neutrophils and macrophages in vivo: endotoxin induces tumor necrosis factor-alpha, macrophage inflammatory protein-2, interleukin-1 beta, and interleukin-6 but not RANTES or transforming growth factor-beta $1 \mathrm{mRNA}$ expression in acute lung inflammation. Am J Respir Cell Mol Biol 10: 148-153.

Zhou H, Ivanov VN, Gillespie J, Geard CR, Amundson SA, Brenner DJ Yu Z, Lieberman HB, Hei TK (2005) Mechanism of radiation-induced bystander effect: role of the cyclooxygenase-2 signaling pathway. Proc Natl Acad Sci USA 102: 14641-14646.

Zhou H, Ivanov VN, Lien YC, Davidson M, Hei TK (2008) Mitochondrial function and nuclear factor-kappaB-mediated signalling in radiationinduced bystander effects. Cancer Res 68: 2233-2240.

This work is published under the standard license to publish agreement. After 12 months the work will become freely available and the license terms will switch to a Creative Commons AttributionNonCommercial-Share Alike 3.0 Unported License. 